\title{
Hybrid subtractive-additive-welding microfabrication for Lab-On-Chip (LOC) applications via single amplified femtosecond laser source
}

\author{
Linas Jonušauskas*a,b, Sima Rekštytè ${ }^{\mathrm{a}}$, Ričardas Buividas ${ }^{\mathrm{c}}$, Simas Butkus $^{\mathrm{a}}$, \\ Roaldas Gadonas $^{\mathrm{a}, \mathrm{b}}$, Saulius Juodkazis*c,d, Mangirdas Malinauskas*a \\ ${ }^{a}$ Laser Research Center, Department of Quantum Electronics, Faculty of Physics, Vilnius University, \\ Saulètekio Ave. 10, Vilnius LT-10223, Lithuania, EU \\ ${ }^{\mathrm{b}}$ Femtika, Sauletekio Ave. 15, LT-10224, Vilnius, Lithuania, EU \\ ${ }^{\mathrm{c} C e n t r e}$ for Micro-Photonics, Swinburne University of Technology, PO Box 218, Hawthorn 3122, Melbourne, \\ Australia \\ ${ }^{\mathrm{d}}$ Melbourne Center for Nanofabrication, Australian National Fabrication Facility, Clayton 3168, Melbourne, \\ Australia
}

\begin{abstract}
An approach employing ultrafast laser hybrid subtractive-additive microfabrication combining ablation, 3D nanolithography and welding is proposed for the realization of Lab-On-Chip (LOC) device. Single amplified $\mathrm{Yb}: \mathrm{KGW}$ fs-pulsed laser source is shown to be suitable for fabricating microgrooves in glass slabs, polymerization of fine-meshes filter out of hybrid organic-inorganic photopolymer SZ2080 inside them, and, lastly, sealing the whole chip with cover glass into a single monolithic piece. The created microfluidic device proved its particle sorting function by separating $1 \mu \mathrm{m}$ and $10 \mu \mathrm{m}$ polystyrene spheres in a mixture. All together, this shows that fs-laser microfabrication technology is a flexible and versatile tool for the manufacturing of mesoscale multi-material LOC devices.
\end{abstract}

Keywords: femtosecond laser 3D microfabrication; 3D printing; nanotechnology; microfluidics; lab-on-chip.

*Send further corespondence to L. Jonušauskas linas@femtika.lt, S. Juodkazis sjuodkazis@swin.edu.au and M. Malinauskas mangirdas.malinauskas@ff.vu.lt

\section{INTRODUCTION}

Since the creation of the laser it became an irreplaceable tool in advanced material processing. ${ }^{1-4}$ The newest development in the field is the application of ultrafast tunable lasers generating pulses in the range from picoseconds (ps) to femtoseconds (fs). This provides a possibility for creating fabrication setups that can realize both additive and subtractive manufacturing in meso-scale dimensions varying from nanometer resolution to overall size in range of $\mathrm{cm} .^{5}$

Recently, huge advances have been done in lab-on-chip (LOC) technologies in terms of their functionality and integrability. ${ }^{6,7}$ One of the current goals in this field is to reduce the price of such chips, making them as affordable as possible for the end-user. ${ }^{8}$ This requires simplification 
of technologies used in their production which can be achieved by combining as many different material processing methods and fabrication steps into one manufacturing setup. Additionally, it might be desired that created microstructures would perform their tasks in passive fashion, i.e. without the use of any external energy source. ${ }^{9,10}$ This is extremely important as it paves the way to use such devices in remote locations short of electricity or accessibility to modern computers.

In this work, we explore the possibility to use an amplified femtosecond Yb:KGW fs-pulsed laser in both subtractive and additive fashions in order to create passive LOC particle separator. First, laser ablation is used to produce channels in glass substrates. Then, 3D laser lithography (3DLL) is employed to integrate microfilters into the channels. Finally, the chip is sealed with glass cover by laser welding. All the steps are performed by employing Yb:KGW amplified fs laser source that can be tuned in terms of output power $(P)$ and repetition rate $(f)$. We demonstrate that integrated filters can act as passive microparticle ( $1 \mu \mathrm{m}$ and $10 \mu \mathrm{m}$ in diameter, medium - water) sorters. Research unveils what channel geometries and sorting protocols are the most efficient. Overall, these results show that multiple technological steps required to produce functional LOC structure can be performed with a single laser source in a hybrid subtractive-additive fabrication approach.

\section{Materials and methods}

In order to create the required structures, four distinct fabrication steps had to be undertaken: direct channel ablation [Fig. 1 (a)], inlet cutting via filament assisted ablation [Fig. 1 (b)], filter polymerization [Fig. 1 (c)], and welding of upper and lower parts of the structure [Fig. 1 (d)]. For the channel preparation, a 1-mm-thick borosilicate glass microscope slide was used. The channels were sealed with $150 \mu \mathrm{m}$ cover glass slide. For the filter mesh fabrication a hybrid organic-inorganic 
photopolymer SZ2080 was chosen as it exhibits high mechanical strength, ${ }^{11}$ wide fabrication window $^{12}$ and, if need arises, could be easily combined with organic ${ }^{13}$ or inorganic ${ }^{14}$ additives for increased functionality. It was mixed with $1 \mathrm{wt} \%$ photoinitiator 2-benzyl-2-dimethylamino-1(4-morpholinophenyl)-butanone-1 (also known as Irgacure 369). One of the advantages of this material is its hard gel-form during fabrication which results in a minimal shrinkage after developing. ${ }^{11}$ The liquid SZ2080 turns into gel during a pre-bake step when the solvent is removed from the mixture. The pre-bake is performed in a "ramp" fashion, with three temperature levels of $40^{\circ} \mathrm{C}, 70^{\circ} \mathrm{C}$ and $90^{\circ} \mathrm{C}$ each lasting $20 \mathrm{~min}$ and separated by 5 minute temperature increase intervals.

Development is done in 4-methyl-2-pentanone for 1 hour. In all these experiments femtosecond Yb:KGW laser "Pharos" (Light Conversion Ltd.) was employed, as it offers tuning range broad enough ( $f=1-200 \mathrm{kHz}, P$ - up to $20 \mathrm{~W}$ ) for both additive and subtractive manufacturing.
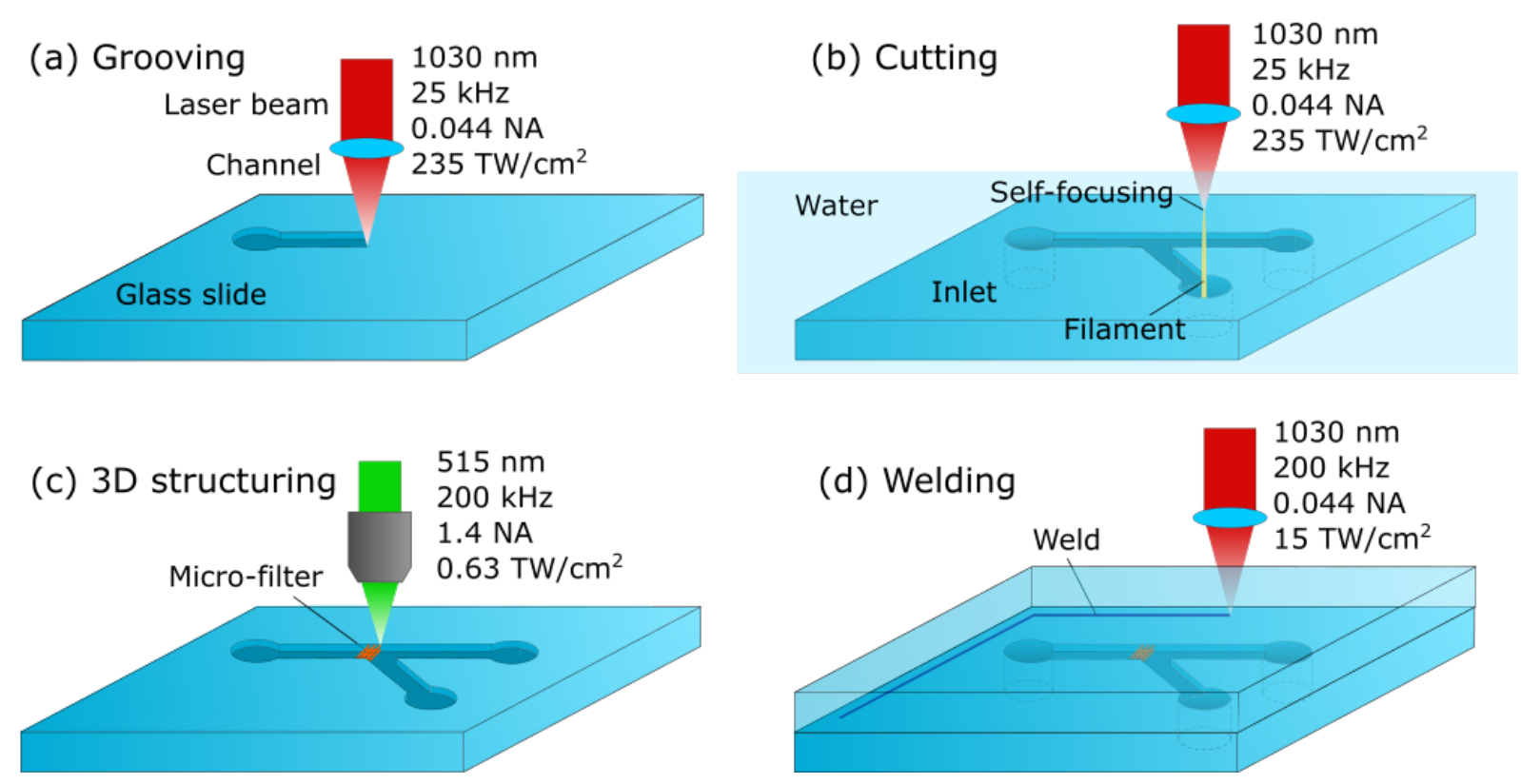

Fig 1 Schematic representation of the processes employed in LOC fabrication: (a) direct ablation is applied to fabricate the channels, (b) filament assisted ablation is used to cut inlets of the system, (c) polymerization is applied for 3D fabrication of integrated filter and (d) laser welding is employed to seal the channel with a glass slide. 
Average laser power was measured prior to fabrication and the peak intensity was calculated by employing following formula:

$$
I_{p}=\frac{2 P T}{f \omega^{2} \pi \tau},
$$

where $f$ is the pulse repetition rate, $\tau$ is the pulse duration, $\omega=0.61 \lambda / N A$ is the waist (radius) of the beam, and $T$ is the transmission of the objective. Exact parameters describing the fabrication process are listed where it applies.

The structural examination was performed using scanning electron microscope (SEM) TM1000 (Hitachi, Ltd.) or an inverted optical microscope setup. Water was used as liquid in all the flow experiments.

\section{Results}

\subsection{Femtosecond manufacturing of glass channels}

The glass is a favorable material for a microfluidic chip as it is mechanically robust, chemically inert and completely transparent in all visible region of the spectrum. The latter property makes it suitable for fluorescence measurements and Raman spectroscopy. ${ }^{15}$ Thus, it was chosen as a model material for channel fabrication in this study.

Glass structuring for microfluidic applications can be performed in several different ways. One of them is the combination of standard lithography and chemical etching. ${ }^{16}$ The idea is based on creation of a polymeric mask onto the glass surface and then etch it in hydrofluoric acid (HF). The limitation of this approach is that there is very little control of channel aspect ratio and how steep the channel walls will be. Alternatively, laser can be used to make strain-induced regions of densified glass network where a Lewis-base structure is created via formation of a small-member- 
structure of tetrahedral rings in silica which are prone to a high contrast etching in HF solution. ${ }^{17,18}$ By recording nano-grating pattern inside glass, an additional directionality of HF etching can be obtained. ${ }^{19}$ This allows a lot of freedom in designing the microfluidic systems. Etching is a diffusion-limited process and is comparatively slow, which poses constrains in selection of glass and etchant. Fused silica is a strongly preferred host for LOC devices as channel etching in HF is comparatively fast in this material. However, due to a hazardous nature of HF etching, in this work, direct laser ablation was employed for the manufacturing of the channels as it is well established method of producing microfluidic channels on the surface of the glass substrates. ${ }^{20}$

The ablation was performed with fundamental $(1030 \mathrm{~nm})$ laser wavelength, 260 fs pulse duration, $25 \mathrm{kHz}$ repetition rate and $235 \mathrm{TW} / \mathrm{cm}^{2}$ peak intensity at the focus of f-theta lens with focal distance of $100 \mathrm{~mm}$. Sample translation velocity was $100 \mathrm{~mm} / \mathrm{s}$. As the laser spot was around $28 \mu \mathrm{m}$ in diameter ( $\mathrm{e}^{-2}$ level), the 200 - $\mu \mathrm{m}$-wide channels were fabricated by raster scanning the sample along direction of channel 11 times. The lateral distance between scans was set to $20 \mu \mathrm{m}$. The depth of a channel was controlled by changing the number of scans performed along the same path. It was established, that the depth of the channel depended on scanning repetitions almost in a linear fashion: 5 consecutive scans provided the depth of $40 \mu \mathrm{m}, 10-70 \mu \mathrm{m}, 15-110 \mu \mathrm{m}, 20-$ $150 \mu \mathrm{m}, 25-190 \mu \mathrm{m}$. The final channels which were tested in this work had a $200 \mu \mathrm{m}$ width and were $100 \mu \mathrm{m}$ deep [Fig. 2]. With these parameters one microfluidic system can be produced in a matter of several minutes.

\subsection{Inlet cutting}

Next challenge was to make sufficiently deep and wide holes for the inlets and outlets of the system. This was achieved by water assisted femtosecond filament ablation. By having a $\sim 1 \mathrm{~mm}-$ 


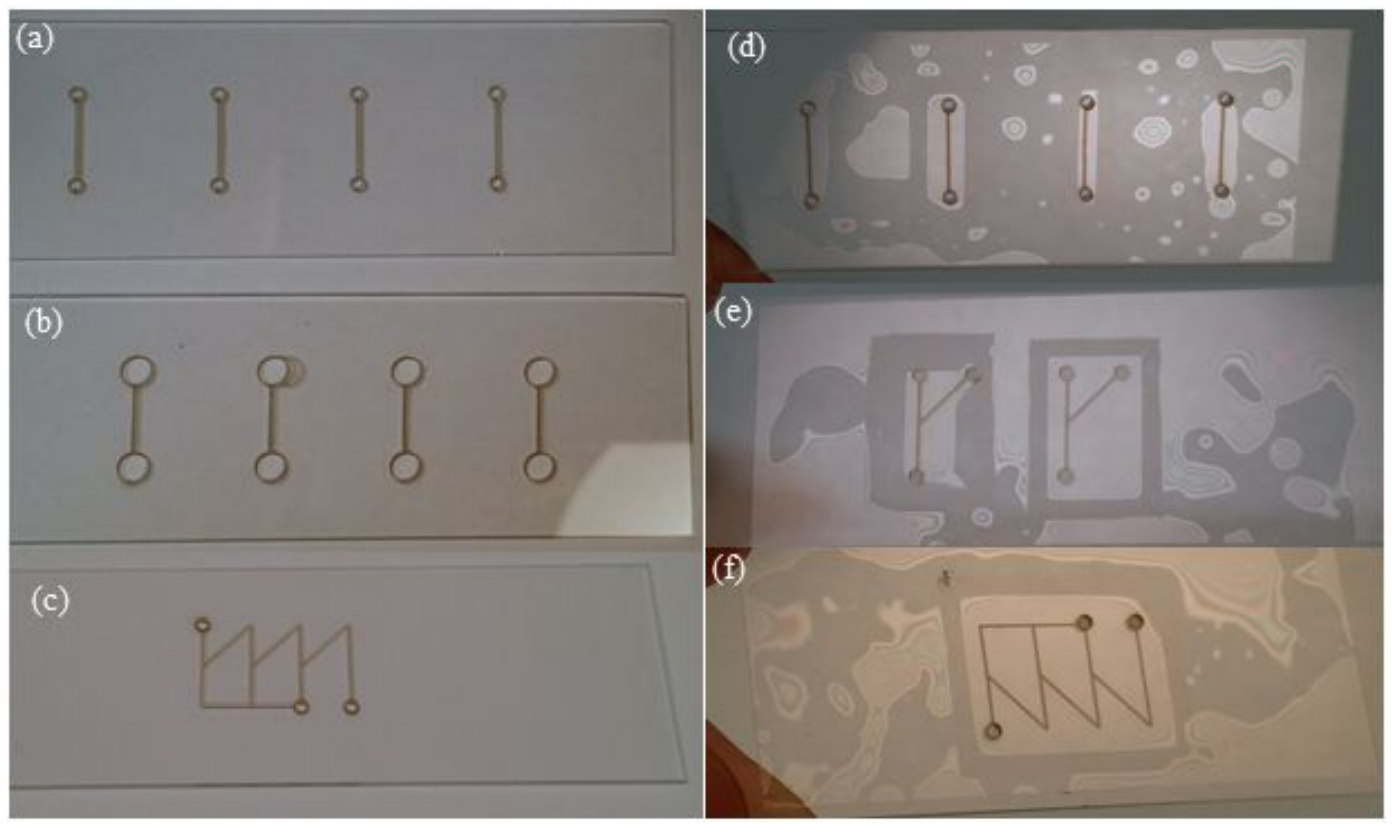

Fig 2 (a)-(c) Fs-laser-cut channel systems in glass slides. (d)-(f) Examples of systems sealed with $150 \mu \mathrm{m}$ glass slides via fs laser welding.

thick water layer above the glass sample, fs-laser radiation focused into the water initiates the formation of a light filament, which is capable of cutting arbitrary shapes in the millimeters-thick samples. In order to increase the efficiency of this method, before submerging glass into water, it was washed with soap making it more hydrophilic. As a result, 1.2-mm-diameter through-holes were successfully cut out. Parameters used in this step were similar to ones applied for direct ablation. More details on this technology can be found elsewhere. ${ }^{21}$

\subsection{Integration of microfilters}

Before sealing the channels, 3DLL was applied to form microfilters in the channels. The experiments were performed with a 1.4 NA objective using second laser harmonic $(515 \mathrm{~nm}), 200 \mathrm{kHz}$ repetition rate, $0.63 \mathrm{TW} / \mathrm{cm}^{2}$ peak intensity and $0.5 \mathrm{~mm} / \mathrm{s}$ sample translation velocity. Because of the versatility of the 3DLL technology, ${ }^{22}$ filters of basically any shape or orientation could be formed inside the channel at the chosen position [Fig. 3]. Thus, the geometry of a filter rotated at 
$45^{\circ}$ was selected [Fig. 3 (f)], as it could be integrated directly into separation channel intersection and conforms with the flow-reflective geometry at the channel's intersection. The microbeads that were intended to be separated were $1 \mu \mathrm{m}$ and $10 \mu \mathrm{m}$ in diameter, thus the chosen pore size was in the middle of this interval - $6 \mu \mathrm{m}$.

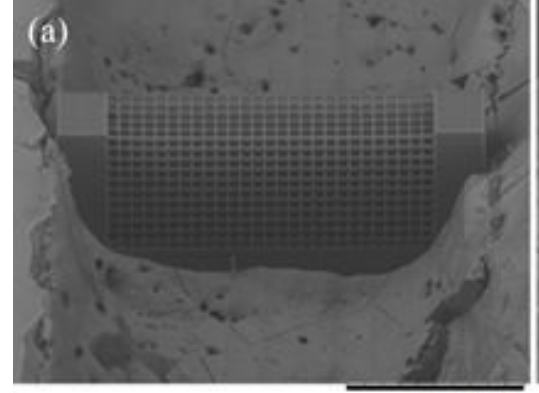

$100 \mu \mathrm{m}$

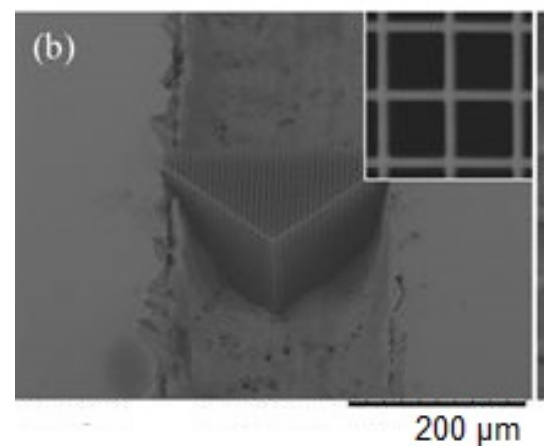

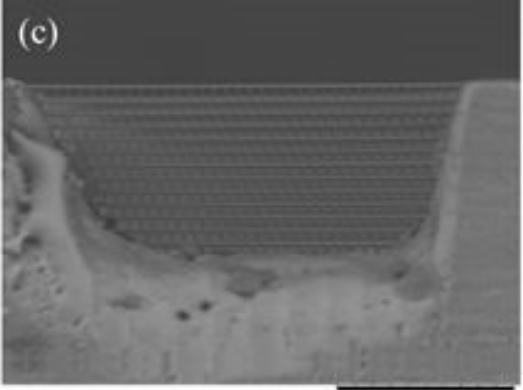

$100 \mu \mathrm{m}$

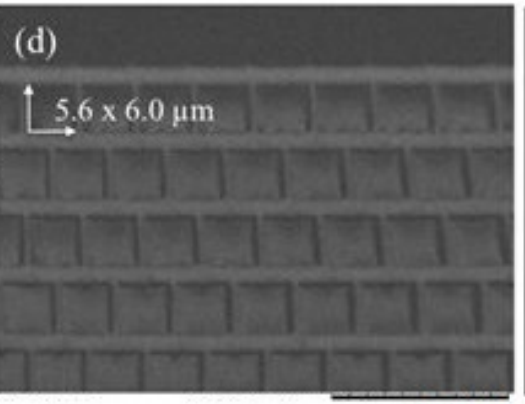

$20 \mu \mathrm{m}$

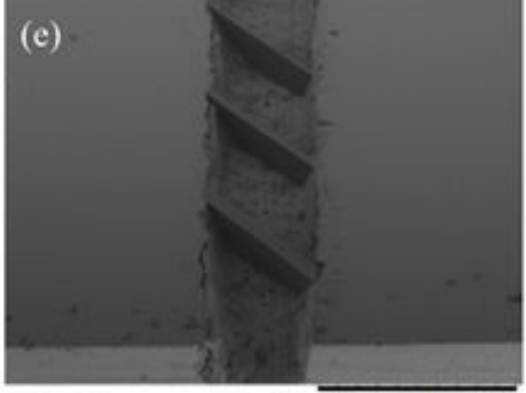

$500 \mu \mathrm{m}$

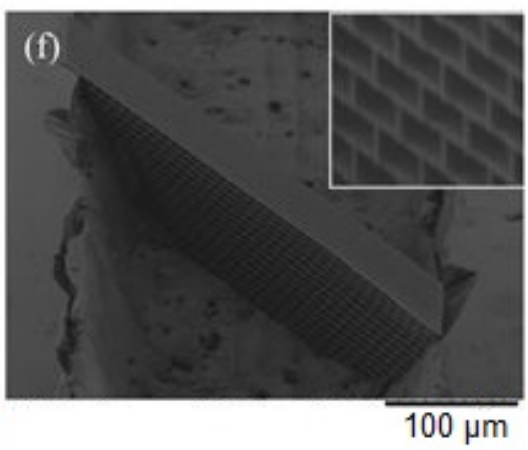

Fig 3 Examples of various polymeric filters integrated into glass channels by 3DLL: (a) a normal-to-flow filter, (b) chevron mesh, (c) a side-view of a filter, showing clear and consistent pores sized around $6 \mu \mathrm{m}$ (d). (e) Demonstration of a possibility to integrate any number of filters (made at an angle) in the channel and magnified view of one of such structures (d).

\subsection{Sealing channels via laser welding}

The laser welding of the channel system and cover glass was the last step in assembling the microfluidic system. ${ }^{23}$ One of the main requirements for a successful welding is to make sure that both glass layers would be in direct contact to each other. In order to achieve that, three strategies were proposed and implemented. The first one was to clean the glass surfaces in an ultrasound bath first in acetone, then in isopropanol and finally in water. After that, in order to remove debris left- 
overs, samples were blow with nitrogen gas and then compressed together. The second approach was to put the glass slides with isopropanol layer between them in a vacuum chamber with the intent of removing isopropanol and making an optical contact. In the last approach, glass slides were cleaned only by acetone and blown with nitrogen before being compressed together. The second approach did not provided satisfactory results as the glass slides were not entirely in contact to one another. The first and the third approach showed consistent results in channel sealing. Thus, because of simplicity, the third strategy was chosen.

The welding was performed using $200 \mathrm{kHz}$ repetition rate, $15 \mathrm{TW} / \mathrm{cm}^{2}$ peak intensity, $10 \mathrm{~mm} / \mathrm{s}$ translation velocity and $1030 \mathrm{~nm}$ wavelength. At these parameters glass melts at the interface between to glass surfaces and permanently bonds them together. Overall 10 rectangular welds spaced apart by $200 \mu \mathrm{m}$ were formed to achieve a sufficiently strong system. The assembled chip with metal pipes secured in the inlet and outlets is shown in Fig. 4.

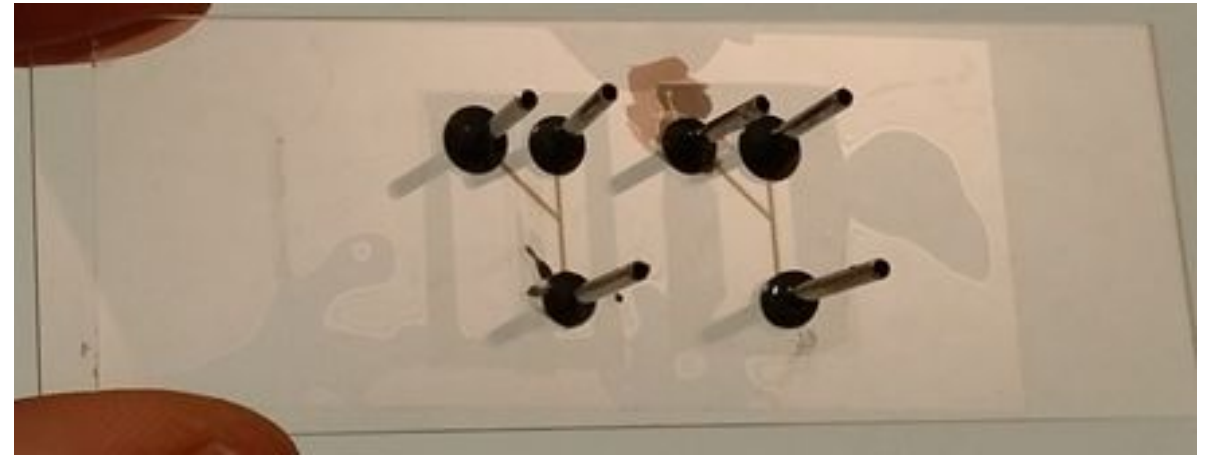

Fig 4 An image of a finished LOC system. The glass channels are prepared and welded over by cover slip. Tubes are glued into their places. Systems in such configuration were used in the flow experiments.

\subsection{Testing of the micro-system}

To prove the concept of particle separation using filter inside such a microfluidic system, a stream of differently sized beads was mixed in liquid and pumped in the system [Fig. 5 (a) blue arrow]. 
The filter only allows smaller particles to pass through [Fig. 5 (a) yellow arrow] while the bigger ones are carried with the main flow [Fig. 5 (a) red arrow]. Unfortunatelly, significant ammount of small particles was carried together with the main flow (red arrow). To improve separation efficiency several different channel geometries were fabricated. Fig. 5 (b) shows geometry with additional wall marked "U" polimerised in order to increase pressure for particles to go via the filter. Fig. 5 (c) serves similar purpose and because of simpler fabrication was chosen for further studies. To further improve separation efficiency 3 stage filtering LOC was fabricated (based on Fig. 5 (c) geometry) shown in figure 6.
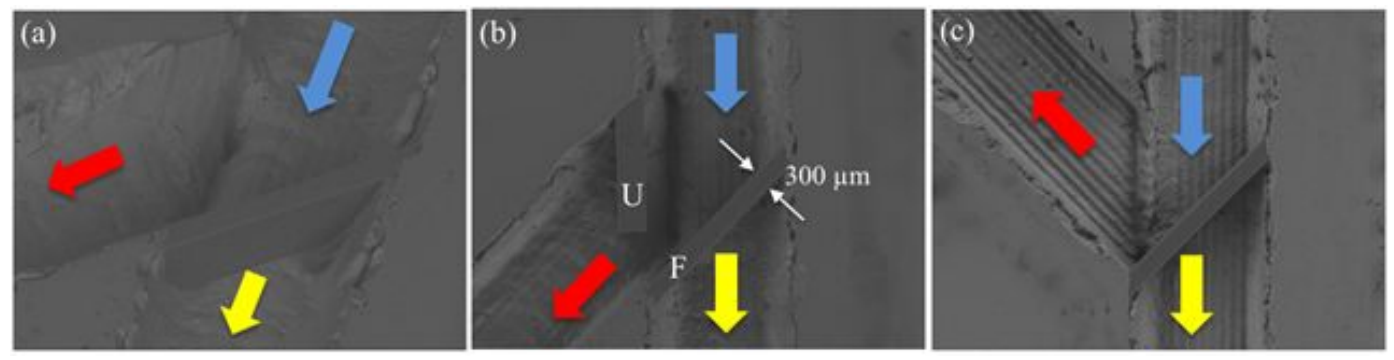

Fig 5 (a) A $45^{\circ}$ intersection with an integrated filter for separation of mixture of $1 \mu \mathrm{m}$ and $10 \mu \mathrm{m}$ beads (blue arrow is incoming stream), flow of the filtered stream (yellow), flow-reflected stream with bigger beads (red). (b) Similar intersection for the filtering mesh but with the wall that was integrated in order to increase flow pressure via the filter. (c) Depicts an inverted channel geometry (reflective flow), when groove for the bigger beads goes to other direction than in (a) or (b). Such configuration proved to be the most efficient in separating the particles and was used in further experiments.

To observe the behavior of the microparticles an inverted microscope setup was utilised. As was previously mentioned, the glass slide chosen for channel sealing was $150 \mu \mathrm{m}$ thick, allowing for high-magnification objective lens which is capable of imaging single beads of both sizes [Fig. 7] to be used for in situ observation of the LOC in action. Clear redirection of larger particles was observed [Fig. 8]. Examination of the liquid after the filtering revealed, that bigger beads are absent. Clogging of the channel was happening if bigger particles started to gather in front of the filters. Such conglomeration of the microbeads was broken by a brief reversion of the liquid flow. 
It was noticed that it is not only effective, but also had no negative impact on the micro-filtering action. In all, the created microfluidic system performed the planned task and was proven to be mechanically robust.

\section{Discussion}

One of the main reasons why laser material processing became so popular in the industry is the fact that basically any material can be processed using laser radiation at tailored high intensity which are required to deliver energy that can be absorbed in order to create modification (melting, ablation, evaporation, ionisation, optical defect formation). ${ }^{4}$ However, so far, in most cases, it was custom to use specially tuned laser source for exact material and/or application. For example, excimer lasers can be used for additive polymer processing,${ }^{24}$ while $\mathrm{CO}_{2}$ lasers were mostly applied for cutting. ${ }^{25}$ However, in case of ultrafast laser sources, because of high light intensity induced nonlinear light-matter interactions, basically all materials can be processed with high precision ${ }^{26}$

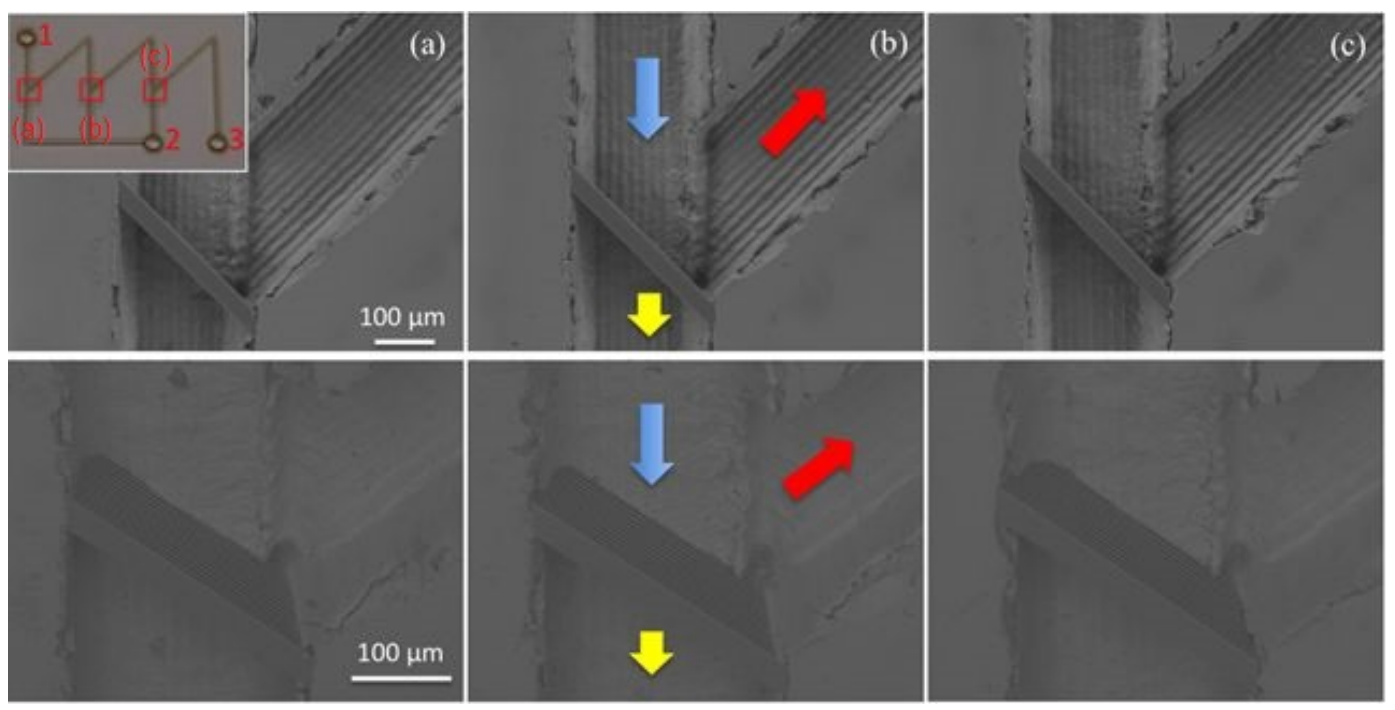

Fig 6 SEM micrographs of 3 consecutive intersections marked (a), (b) and (c) in a 3 level filtering LOC system. Good repeatability of both ablated channels and integrated filters is evident. The view of a whole system is provided in the inset in (a). Inlet 1 is used to introduce the liquid with different sized particles. The smaller ones are filtered out and directed to outlet 2, while bigger ones - into 3. 


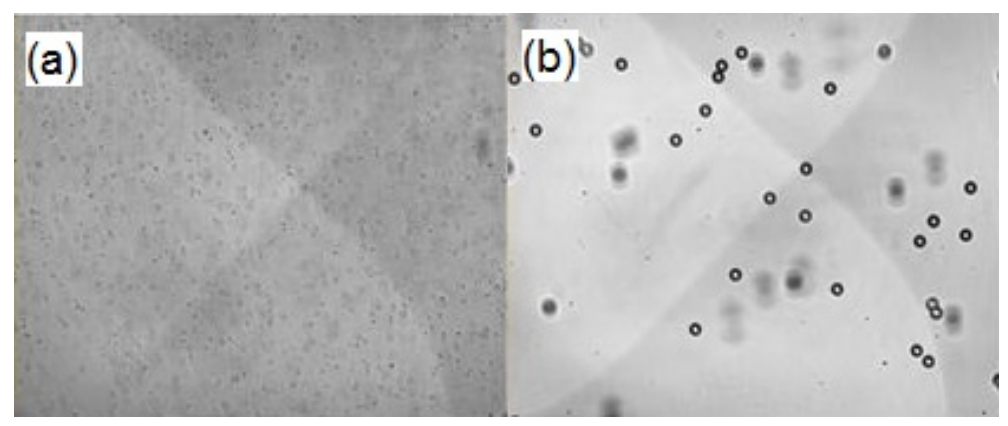

Fig 7 (a) and (b) Images of $1 \mu \mathrm{m}$ and $10 \mu \mathrm{m}$ beads (respectively) showing good image quality of applied microscope.

in both subtractive and additive fashion. ${ }^{5}$ For instance, in case of presented results, the intensity needed for polymerization was around $0.63 \mathrm{TW} / \mathrm{cm}^{2}$ (additive process of polymerisation), while it was $235 \mathrm{TW} / \mathrm{cm}^{2}$ during ablation (subtractive). Furthermore, tunning of the pulse repetition rate allows to switch between regimes with minimal thermal effects while operating at low repetition rates ( $\sim \mathrm{kHz}$, so called "cold processing") to severe heating in and around focal volume with higher ( $\sim$ hundreds $\mathrm{kHz}$ ) pulse repetition rate. It is important, as the best results during ablation are achieved in the former regime, while it is crucial to operate in the latter during laser welding. ${ }^{2}$

One of the most delicate procedures to accomplish is fs-laser welding of the micro-channel
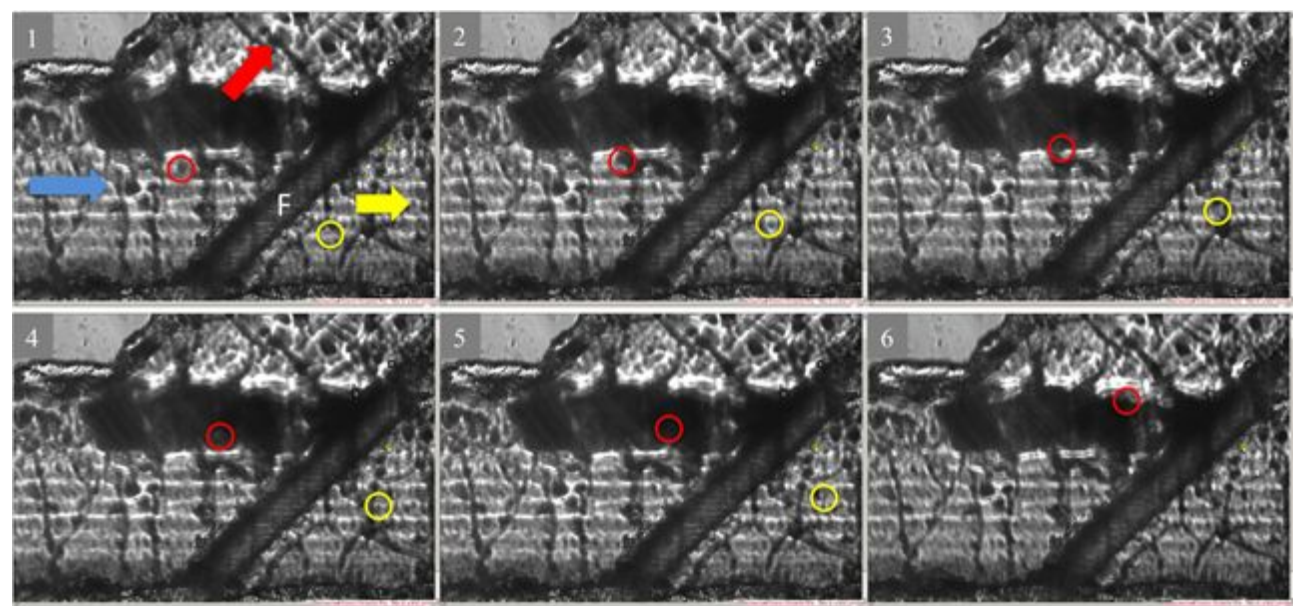

Fig 8 Real time imaging (numbers 1-6 mark the evolution in time) of filtering in the produced LOC system. Circles mark either smaller (yellow) or bigger (red) particles. Clear separation of beads and mechanical strength of the filter (i.e. no damage to it by the stream) is evident. 
cover sealing. It has been already demonstrated that fs-laser welding can reach $\sim 30 \mathrm{MPa}$ tensile and up to twice higher shear strength. ${ }^{27,28}$ Such mechanical sealing strength is higher than a typical plastic lamination used in Si-based microfluidic chips and allows to handle fast flows. ${ }^{29}$ It is critical to have separation gap comparable with the axial extent of the focal spot of the laser beam and this places a requirement of 1-2 $\mu \mathrm{m}$ between the channel substrate and cover. Strength of the cover welding is controlled by increasing the surface area of the joint region.

Both additive and subtractive fs laser fabrication methods have some distinct advantages and drawbacks. The subtractive manufacturing offers a way to rapidly produce various structures that are embedded into a surface of the sample, such as channels ${ }^{30}$ or hydro-active surfaces. ${ }^{31}$ Yet it lacks the possibility to easily produce true 3D structures. On the other hand, additive manufacturing realized with ultrafast laser is superb in creating and integrating true $3 \mathrm{D}$ structures on a wide array of substrates ${ }^{32}$ and structures. ${ }^{10,33-35}$ What is more, it allows multimaterial fabrication during formation of single structure thus enabling 4D printing. ${ }^{9,36}$ However, as it is based on a point-by-point structuring, it lacks the throughput to fabricate the whole LOC system fast enough to be commercially viable. ${ }^{37}$ Merging these two approaches in one hybrid manufacturing system is a promising prospect, as it reduces the number of required setups (and light sources) to a single one while combining the advantages and eliminating drawbacks of both of these approaches.

Alternatives for producing a fully functioning microfluidic system with either only subtractive or additive manufacturing are also possible, yet a bit more complicated. Combining standard 3D printing with 3DLL seems as one of the possible ways to go. ${ }^{38}$ In that case the throughput sufficient for LOC fabrication is guaranteed by the $3 \mathrm{D}$ printer, ${ }^{39}$ while $3 \mathrm{DLL}$ is used for structure integration $^{10,22}$ and guarantees nano-level precision in fabrication. ${ }^{40}$ In subtractive case some promising results were achieved in selective glass or crystal (sapphire) etching. ${ }^{41}$ Volume-embedded struc- 
tures were produced this way, hinting at emerging true 3D capabilities of this approach.

Overall, the driving force behind all these advances is the prospect of creating fully integrated microfluidic systems. The fs-ablation, which was employed in this work, can only pattern the surface of the sample, thus we create channel system that is Lab-On-Chip. In contrast, if unlimited freedom in the design and manufacturing would be easily obtainable, the multilayer Lab-In-Chip (LIC) type devices with fully integrated channels would become possible. The main attractiveness of such systems would be due to the fact, that their efficiency increases by a factor of 3 with an increase of one dimension of the system (as it is integrated in the volume of the material). This makes a huge difference, as current flat (2D)-based systems scale by factor of 2 with the increase in one dimension. Nevertheless, despite laser produced channels in the volume of glass and fully integrated polymeric structures, a lot of work has to be done before this vision becomes a widespread solution.

\section{Conclusions}

In this work a hybrid subtractive-additive-welding fs-laser fabrication was employed to produce a functional microfluidical system capable of sorting different sized $(1 \mu \mathrm{m}$ and $10 \mu \mathrm{m})$ microparticles. This was enabled by the widely tunable (in power $P$ and repetition rate $f$ ) $\mathrm{Yb}: \mathrm{KGW}$ amplified fs-laser system. Microfluidical chip was proven to be mechanically robust, including both the channel network and 3D polymeric microfilter. The presented results clearly demonstrate that combining hybrid subtractive-additive laser fabrication technologies to create complex functional LOC systems is a prudent approach that could lead to the best overall result. The demonstrated all-in-glass fabrication of LOC using tailored fs-laser fabrication is compatible with all-in-plastic platform widely used in bio-medical applications while the multi-step filtering can be promising 
for integration into fluidic bactericidal filters based on nanoscale roughness. ${ }^{42}$

\section{Acknowledgments}

Authors acknowledge NATO SPS-985048 Nanostructures for Highly Efficient Infrared Detection grant and European Commissions's Seventh Framework Programme Laserlab-Europe IV JRA support BIOAPP (EC-GA 654148). Dr. L. Mažutis from the Institute of Biotechnology (Vilnius University) is acknowledged for the provision of microbeads. This paper is a follow-up to a SPIE proceeding 10115-33.

\section{References}

1 F. P. Gagliano, R. M. Lumley, and L. S. Watkins, "Lasers in industry," Proc. IEEE 57(2), pp. $114-147,1969$.

2 K. Sugioka and Y. Cheng, "Femtosecond laser three-dimensional micro- and nanofabrication," Appl. Phys. Rev. 1, p. 041303, 2014.

3 R. R. Gattass and E. Mazur, "Femtosecond laser micromachining in transparent materials," Nat. Photon. 2, pp. 219-225, 2008.

4 W. M. Steen, “Laser material processing-an overview," J. Opt. 5(4), pp. S3-S7, 2003.

5 M. Malinauskas, A. Žukauskas, S. Hasegawa, Y. Hayasaki, V. Mizeikis, R. Buividas, and S. Juodkazis, "Ultrafast laser processing of materials: from science to industry," Light Sci. Appl. 5(8), p. e16133, 2016.

6 P. Abgrall and A.-M. Gué, "Lab-on-chip technologies: making a microfluidic network and coupling it into a complete microsystem - a review," J. Micromech. Microeng. 17(5), pp. R15R49, 2007. 
7 L. Mazutis, J. Gilbert, W. L. Ung, D. A. Weitz, A. D. Griffiths, and J. A. Heyman, "Singlecell analysis and sorting using droplet-based microfluidics," Nat. Protoc. 8(5), pp. 870-891, 2013.

8 G. Comina, A. Suska, and D. Filippini, "Low cost lab-on-a-chip prototyping with a consumer grade 3D printer," Lab Chip 14(16), pp. 2978-2982, 2014.

9 S. Rekštytė, D. Paipulas, M. Malinauskas, and V. Mizeikis, "Microactuation and sensing using reversible deformations of laser-written polymeric structures," Nanotechnology 28(12), p. $124001,2017$.

10 L. Amato, Y. Gu, N. Bellini, S. M. Eaton, G. Cerullo, and R. Osellame, "Integrated threedimensional filter separates nanoscale from microscale elements in a microfluidic chip," Lab Chip 12(6), pp. 1135-1142, 2012.

11 A. Ovsianikov, J. Viertl, B. Chichkov, M. Oubaha, B. MacCraith, I. Sakellari, A. Giakoumaki, D. Gray, M. Vamvakaki, M. Farsari, and C. Fotakis, "Ultra-low shrinkage hybrid photosensitive material for two-photon polymerization microfabrication," ACS Nano 2(11), pp. 2257$2262,2008$.

12 L. Jonušauskas, D. Gailevičius, L. Mikoliūnaitė, D. Sakalauskas, S. Šakirzanovas, S. Juodkazis, and M. Malinauskas, "Optically clear and resilient free-form $\mu$-optics 3D-printed via ultrafast laser lithography,” Materials 10(1), p. 12, 2017.

13 A. Žukauskas, M. Malinauskas, L. Kontenis, V. Purlys, D. Paipulas, M. Vengris, and R. Gadonas, "Organic dye doped microstructures for optically active functional devices fabricated via two-photon polymerization technique," Lith. J. Phys. 50(1), pp. 55-61, 2010.

14 L. Jonušauskas, M. Lau, P. Gruber, B. Gökce, S. Barcikowski, M. Malinauskas, and 
A. Ovsianikov, "Plasmon assisted 3D microstructuring of gold nanoparticle-doped polymers," Nanotechnology 27(15), p. 154001, 2016.

15 K. R. Strehle, D. Cialla, P. Rösch, T. Henkel, M. Köhler, and J. Popp, "A reproducible surface-enhanced raman spectroscopy approach. online SERS measurements in a segmented microfluidic system," Anal. Chem. 79(4), pp. 1542-1547, 2007.

16 A. Grosse, M. Grewe, and H. Fouckhardt, "Deep wet etching of fused silica glass for hollow capillary optical leaky waveguides in microfluidic devices," J. Micromech. Microeng. 11(3), pp. 257-262, 2001.

17 A. Marcinkevicius, S. Juodkazis, M. Watanabe, M. Miwa, S. Matsuo, H. Misawa, and J. Nishii, "Femtosecond laser-assisted three-dimensional microfabrication in silica," Opt. Lett. 26(5), pp. 277-279, 2001.

18 S. Juodkazis, K. Yamasaki, V. Mizeikis, S. Matsuo, and H. Misawa, "Formation of embedded patterns in glasses using femtosecond irradiation," Appl. Phys. A 79(4-6), pp. 1549 - 1553, 2004.

19 C. Hnatovsky, R. S. Taylor, E. Simova, V. R. Bhardwaj, D. M. Rayner, and P. B. Corkum, "Polarization-selective etching in femtosecond laser-assisted microfluidic channel fabrication in fused silica," Opt. Lett. 30(14), pp. 1867-1869, 2005.

20 I. Goenaga, "Femtosecond laser ablation for microfluidics," Opt. Eng. 44(5), p. 051105, 2005.

21 S. Butkus, E. Gaižauskas, D. Paipulas, Ž. Viburys, D. Kaškelyė, M. Barkauskas, A. Alesenkov, and V. Sirutkaitis, "Rapid microfabrication of transparent materials using filamented femtosecond laser pulses," Appl. Phys. A 114(1), pp. 81-90, 2013.

22 J. Wang, Y. He, H. Xia, L.-G. Niu, R. Zhang, Q.-D. Chen, Y.-L. Zhang, Y.-F. Li, S.-J. Zeng, 
J.-H. Qin, B.-C. Lin, and H.-B. Sun, "Embellishment of microfluidic devices via femtosecond laser micronanofabrication for chip functionalization," Lab Chip 10(15), pp. 1993-1996, 2010.

23 T. Tamaki, W. Watanabe, J. Nishii, and K. Itoh, "Welding of transparent materials using femtosecond laser pulses,” Jpn. J. Appl. Phys. 44(22), pp. L687-L689, 2005.

24 B. Farkas, S. Dante, and F. Brandi, "Photoinitiator-free 3D scaffolds fabricated by excimer laser photocuring," Nanotechnology 28(3), p. 034001, 2016.

25 B. S. Yilbaş, "Experimental investigation into CO2 laser cutting parameters," J. Mater. Process. Technol. 58(2-3), pp. 323-330, 1996.

26 B. N. Chichkov, C. Momma, S. Nolte, F. Alvensleben, and A. Tnnermann, "Femtosecond, picosecond and nanosecond laser ablation of solids," Appl. Phys. A 63(2), pp. 109-115, 1996.

27 S. Richter, S. Döring, A. Tünnermann, and S. Nolte, "Bonding of glass with femtosecond laser pulses at high repetition rates," Appl. Phys. A 103(2), pp. 257-261, 2011.

28 T. Tamaki, W. Watanabe, J. Nishii, and K. Itoh, "Welding of transparent materials using femtosecond laser pulses," Jpn. J. Appl. Phys. 44(22), pp. L687-L689, 2005.

29 G. Gervinskas, D. J. Day, and S. Juodkazis, “Optofluidic fabry-pérot sensor for water solutions at high flow rates," Opt. Mater. Express 2(3), pp. 279-286, 2012.

30 O. A. Araromi, S. Rosset, and H. R. Shea, "High-resolution, large-area fabrication of compliant electrodes via laser ablation for robust, stretchable dielectric elastomer actuators and sensors," ACS Appl. Mater. Interfaces 7(32), pp. 18046-18053, 2015.

31 M. H. Kwon, H. S. Shin, and C. N. Chu, "Fabrication of a super-hydrophobic surface on metal using laser ablation and electrodeposition,” Appl. Surf. Sci. 288, pp. 222-228, 2014. 
32 S. Rekštytė, T. Jonavičius, and M. Malinauskas, "Direct laser writing of microstructures on optically opaque and reflective surfaces," Opt. Laser Eng. 53, pp. 90-97, 2014.

33 M. Malinauskas, G. Kiršanskė, S. Rekštytė, T. Jonavičius, E. Kaziulionytė, L. Jonušauskas, A. Žukauskas, R. Gadonas, and A. Piskarskas, "Nanophotonic lithography: a versatile tool for manufacturing functional three-dimensional micro-/nano-objects," Lith. J. Phys. 52(4), pp. 312-326, 2012.

34 S. Lightman, R. Gvishi, G. Hurvitz, and A. Arie, "Shaping of light beams by 3D direct laser writing on facets of nonlinear crystals," Opt. Lett. 40, pp. 4460-4463, sep 2015.

35 T. Gissibl, S. Thiele, A. Herkommer, and H. Giessen, "Two-photon direct laser writing of ultracompact multi-lens objectives," Nat. Photon. 10(8), pp. 554-560, 2016.

36 B. Richter, V. Hahn, S. Bertels, T. K. Claus, M. Wegener, G. Delaittre, C. B.-Kowollik, and M. Bastmeyer, "Guiding cell attachment in 3D microscaffolds selectively functionalized with two distinct adhesion proteins," Adv. Mater. 29(5), p. 1604342, 2016.

37 D. Ricci, M. Nava, T. Zandrini, G. Cerullo, M. Raimondi, and R. Osellame, "Scaling-up techniques for the nanofabrication of cell culture substrates via two-photon polymerization for industrial-scale expansion of stem cells," Materials 10(1), p. 66, 2017.

38 L. Jonušauskas, E. Skliutas, S. Butkus, and M. Malinauskas, "Custom on demand 3D printing of functional microstructures," Lith. J. Phys. 55(3), pp. 227-236, 2015.

39 N. Bhattacharjee, A. Urrios, S. Kang, and A. Folch, “The upcoming 3D-printing revolution in microfluidics," Lab Chip 16(10), pp. 1720-1742, 2016.

40 S. Rekštytė, T. Jonavičius, D. Gailevičius, M. Malinauskas, V. Mizeikis, E. G. Gamaly, and 
S. Juodkazis, "Nanoscale precision of 3D polymerization via polarization control," Adv. Opt. Mater. 4(8), pp. 1209-1214, 2016.

41 M. Hörstmann-Jungemann, J. Gottmann, and M. Keggenhoff, “3D-microstructuring of sapphire using fs-laser irradiation and selective etching," J. Laser Micro. Nanoeng. 5(2), pp. 145$149,2010$.

42 X. W. Wang, C. Bhadra, T. H. Yen Dang, R. Buividas, J. Wang, R. J. Crawford, E. P. Ivanova, and S. Juodkazis, "A bactericidal microfluidic device constructed using nano-textured black silicon,” RSC Advances 6(31), pp. 26300 - 26306, 2016.

Linas Jonušauskas received his master degree in laser physics in Vilnius University 2016. He is currently working on his $\mathrm{PhD}$ thesis with the main interest in ultrafast laser 3D nanolithography and its applications. In the autumn of 2015 he also become a part of a high-tech company "Femtika" which aims at commercializing femtosecond laser 3D nanofabrication. His scientific interests include ultrafast lasers, laser material processing, applied physics, 3D printing, photonics, integrated microoptics and similar.

Sima Rekštytė defended her $\mathrm{PhD}$ thesis on the topic of direct laser writing in pre-polymers in 2016 at Vilnius University. Her main research interests are fabrication of functional polymeric structures for bio-applications, regenerative medicine and microsensors by employing ultrafast laser material processing.

Saulius Juodkazis is interested in light-matter interactions occurring in a small space and on ultrashort time domains. He is a professor of nanophotonics and a director of nanotechnology facility at Swinburne University of Technology, Melbourne, Australia. S. Juodkazis received a joint cotutelle 
$\mathrm{PhD}$ in material science and experimental physics from Vilnius University, Lithuania, and Lyon-I University, Lyon, France, in 1998.

Mangirdas Malinauskas studies ultrafast light-matter interaction fundamental mechanisms and its practical applications towards advanced 3D optical printing for integrated microoptics and novel biomedicine. He is a senior researcher at Laser Research Center of Vilnius University, Lithuania. M. Malinauskas received a PhD in Physics from Vilnius University on laser-material 3D nanostructuring of polymers for functional microdevices (2010, supervisor Prof. R. Gadonas).

Biographies of the other authors are not available.

\section{List of Figures}

1 Schematic representation of the processes employed in LOC fabrication: (a) direct ablation is applied to fabricate the channels, (b) filament assisted ablation is used to cut inlets of the system, (c) polymerization is applied for 3D fabrication of integrated filter and (d) laser welding is employed to seal the channel with a glass slide.

2 (a)-(c) Fs-laser-cut channel systems in glass slides. (d)-(f) Examples of systems sealed with $150 \mu \mathrm{m}$ glass slides via fs laser welding.

3 Examples of various polymeric filters integrated into glass channels by 3DLL: (a) a normal-to-flow filter, (b) chevron mesh, (c) a side-view of a filter, showing clear and consistent pores sized around $6 \mu \mathrm{m}(\mathrm{d})$. (e) Demonstration of a possibility to integrate any number of filters (made at an angle) in the channel and magnified view of one of such structures (d). 
4 An image of a finished LOC system. The glass channels are prepared and welded over by cover slip. Tubes are glued into their places. Systems in such configuration were used in the flow experiments.

5 (a) $\mathrm{A} 45^{\circ}$ intersection with an integrated filter for separation of mixture of $1 \mu \mathrm{m}$ and $10 \mu \mathrm{m}$ beads (blue arrow is incoming stream), flow of the filtered stream (yellow), flow-reflected stream with bigger beads (red). (b) Similar intersection for the filtering mesh but with the wall that was integrated in order to increase flow pressure via the filter. (c) Depicts an inverted channel geometry (reflective flow), when groove for the bigger beads goes to other direction than in (a) or (b). Such configuration proved to be the most efficient in separating the particles and was used in further experiments.

6 SEM micrographs of 3 consecutive intersections marked (a), (b) and (c) in a 3 level filtering LOC system. Good repeatability of both ablated channels and integrated filters is evident. The view of a whole system is provided in the inset in (a). Inlet 1 is used to introduce the liquid with different sized particles. The smaller ones are filtered out and directed to outlet 2, while bigger ones - into 3.

7 (a) and (b) Images of $1 \mu \mathrm{m}$ and $10 \mu \mathrm{m}$ beads (respectively) showing good image quality of applied microscope.

8 Real time imaging (numbers 1-6 mark the evolution in time) of filtering in the produced LOC system. Circles mark either smaller (yellow) or bigger (red) particles. Clear separation of beads and mechanical strength of the filter (i.e. no damage to it by the stream) is evident. 